\title{
Ibuprofen and/or paracetamol (acetaminophen) for pain relief after surgical removal of lower wisdom teeth, a Cochrane systematic review
}
IN BRIEF
- Provides a summary of the best current evidence on the efficacy of paracetamol and ibuprofen using the third molar pain model.
- Compares the analgesic capabilities of the two agents.
- Considers the evidence for using a single drug that contains both active analgesics.
- Précises the findings from this review in light of other Cochrane reviews in the field.

\author{
E. Bailey, ${ }^{* 1}$ H. Worthington ${ }^{1}$ and P. Coulthard ${ }^{1}$
}

VERIFIABLE CPD PAPER

\begin{abstract}
This paper compares the beneficial and harmful effects of paracetamol, ibuprofen and the novel combination of both in a single tablet for pain relief following the surgical removal of lower wisdom teeth. In this systematic review only randomised controlled double-blinded clinical trials were included. We calculated the proportion of patients with at least $50 \%$ pain relief at 2 and 6 hours post dosing, along with the proportion of participants using rescue medication at 6 and 8 hours. Adverse events were also analysed. Data was meta-analysed where possible. Seven studies were included with a total of 2,241 participants enrolled. Ibuprofen $400 \mathrm{mg}$ is superior to 1,000 $\mathrm{mg}$ paracetamol with a risk ratio for at least $50 \%$ pain relief at 6 hours of 1.47 (95\% confidence interval $[\mathrm{Cl}] 1.28$ to 1.69 ). For the combined drug, the risk ratio for at least $50 \%$ maximum pain relief over 6 hours is 1.77 (95\% Cl 1.32 to 2.39) based on total pain relief (TOTPAR) data. There is high quality evidence that ibuprofen is superior to paracetamol. The novel combination drug shows encouraging results when compared to the single drugs (based on two trials).
\end{abstract}

\section{INTRODUCTION}

This article is based on the Cochrane review Ibuprofen and/or paracetamol (acetaminophen) for pain relief after surgical removal of lower wisdom teeth ${ }^{1}$ published in the Cochrane Database of Systematic Reviews (CDSR) 2013. Cochrane reviews are regularly updated as new evidence emerges and in response to feedback, and the CDSR should be consulted for the most recent version of the review.

\section{BACKGROUND}

The removal of wisdom teeth is an extremely common surgical procedure with hospital episode statistics estimating that 77,000 patients underwent such a procedure during the year 2009/10. ${ }^{2}$ Research suggests that wisdom tooth removal has an immediate negative impact on patients' working and social lives: in one study patients took an average of 1.6 days off work, with over one third of patients stating that the surgery

'University of Manchester, School of Dentistry, Higher Cambridge Street, Manchester, M13 9PL

*Correspondence to: Mr Edmund Bailey

Email:Edmund.bailey@manchester.ac.uk

\section{Refereed Paper}

Accepted 18 February 2014

DOI: $10.1038 /$ sj.bdj.2014.330

${ }^{\circ}$ British Dental Journal 2014; 216: 451-455 had affected their performance at work. ${ }^{3}$ Participation in social activities, sports and other hobbies is also negatively affected. ${ }^{4}$ For many patients quality of life (QoL) is reduced for one to two weeks following surgery. ${ }^{5}$ Postoperative complications may include swelling, bruising and limited mouth opening along with difficulty with eating, which can be a major concern to patients and has not been appreciated by healthcare professionals in the past. ${ }^{6}$ However, patients are often most concerned about postoperative pain, which may be severe. Approximately one in two patients will experience pain despite analgesic therapy, even one week after surgery. ${ }^{5}$ The pain experienced after oral surgery is a validated and widely used pain model for the clinical evaluation of analgesic efficacy. ${ }^{7}$

Paracetamol (acetaminophen) and ibuprofen are commonly prescribed analgesics used extensively in the management of postoperative third molar pain. ${ }^{8,9}$ In 2010, a novel drug marketed as Nuromol was introduced in the UK, ${ }^{10}$ this single tablet includes both paracetamol and ibuprofen. Early trials have shown encouraging data on its analgesic efficacy, ${ }^{10-12}$ and we were keen to include this new drug in our meta-analyses. Recent systematic reviews ${ }^{13,14}$ have looked at the efficacy and safety of ibuprofen and paracetamol individually, without direct comparison, for postoperative pain management. These reviews have included the findings of studies involving a wide variety of types of surgery such as inguinal hernia surgery, caesarean section, orthopaedic surgery and the removal of wisdom teeth. Only one review to date looks at paracetamol specifically in relation to postoperative third molar removal pain, ${ }^{15}$ although two other reviews of single dose postoperative analgesics include subgroup analyses for dental pain only. ${ }^{13,16}$ There is some debate as to whether dental pain is different from other pain. It has been suggested that the effect of certain analgesics including tramadol is worse for dental pain than for other types of postsurgical pain. ${ }^{17}$

\section{OBJECTIVES}

In this review we investigated the optimal dose of ibuprofen versus paracetamol by direct comparison, taking into account the side effects of different doses of the drugs. This would inform dentists, oral surgeons and their patients of the optimal strategy for best pain relief when considering ibuprofen or paracetamol (or a combination of both) following the surgical removal of wisdom teeth. 


\begin{tabular}{|c|c|c|c|c|c|c|c|}
\hline & $\begin{array}{l}\text { Daniels } \\
2009\end{array}$ & $\begin{array}{l}\text { Forbes } \\
1990\end{array}$ & $\begin{array}{l}\text { Hersch } \\
2000^{*}\end{array}$ & $\begin{array}{l}\text { Mehlisch } \\
1995\end{array}$ & $\begin{array}{l}\text { Mehlisch } \\
2010\end{array}$ & $\begin{array}{l}\text { Mehlisch } \\
\text { 2010a }\end{array}$ & $\begin{array}{l}\text { Olson } \\
2001^{*}\end{array}$ \\
\hline Paracetamol $500 \mathrm{mg}$ & & & & & & $x$ & \\
\hline Paracetamol $600 \mathrm{mg}$ & & $x$ & & & & & \\
\hline Paracetamol 1,000 mg & $x$ & & $x$ & $x$ & $x$ & $x$ & $x$ \\
\hline Ibuprofen 200 mg & & $x$ & & & & $x$ & \\
\hline Ibuprofen 400 mg & $x$ & $x$ & $x$ & $x$ & $x$ & $x$ & $x$ \\
\hline Ibuprofen 512 mg & $x$ & & & & & & \\
\hline $\begin{array}{l}\text { Paracetamol } 250 \mathrm{mg} / \\
\text { Ibuprofen } 100 \mathrm{mg}\end{array}$ & & & & & & $x$ & \\
\hline $\begin{array}{l}\text { Paracetamol } 500 \mathrm{mg} / \\
\text { Ibuprofen } 200 \mathrm{mg}\end{array}$ & & & & & $x$ & $x$ & \\
\hline $\begin{array}{l}\text { Paracetamol 1,000 mg/ } \\
\text { Ibuprofen } 400 \mathrm{mg}\end{array}$ & & & & & $x$ & $x$ & \\
\hline
\end{tabular}

Table 2 Five domains for risk of bias

\begin{tabular}{|l|l|}
\hline Bias & Criteria for low risk of bias in included studies \\
\hline Random sequence generation (selection bias) & Method of randomisation must be clearly stated \\
\hline Allocation concealment (selection bias) & $\begin{array}{l}\text { Method for blinding all parties involved in the study } \\
\text { must be detailed }\end{array}$ \\
\hline Incomplete outcome data (attrition bias) & $\begin{array}{l}\text { All primary outcome measures must be reported on } \\
\text { as detailed in the method }\end{array}$ \\
\hline Selective reporting (reporting bias) & $\begin{array}{l}\text { All drop outs and missing data must be accounted } \\
\text { for, adverse events must be included in the analysis }\end{array}$ \\
\hline Other bias & $\begin{array}{l}\text { Method of anaesthetic given is clearly defined and } \\
\text { unlikely to be a cause of bias in the trail }\end{array}$ \\
\hline
\end{tabular}

\section{DESIGN}

This review was completed according to the Cochrane handbook for systematic reviews of interventions. ${ }^{18}$ More information on the work of the Oral Health Group is available online. ${ }^{19}$

\section{SUBJECTS AND METHODS}

All included studies were randomised controlled double-blinded clinical trials. Crossover studies were included provided there was a wash out period of at least 14 days.

\section{Participants}

Patients of all health states without intolerances/ allergies to the study drugs who required the surgical removal of a lower wisdom tooth or teeth that required bone removal or at least registering a baseline pain intensity of moderate to severe pain. Patients who required removal of an additional tooth or teeth were also included. Surgery was undertaken under local anaesthesia, intravenous sedation or general anaesthesia. Patients taking concurrent analgesia were excluded.

\section{Interventions}

Ibuprofen, paracetamol or a combination of both given as a single dose postoperatively

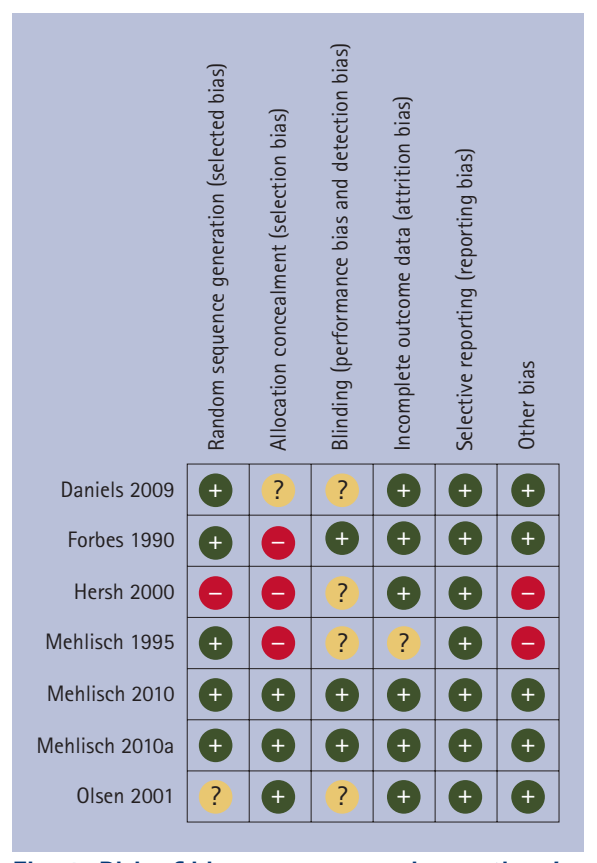

Fig. 1 Risk of bias summary: review authors judgements about each risk of bias item for each included study. Key: red = high risk of bias; yellow $=$ unclear risk of bias; green $=$ low risk of bias

\section{OUTCOME MEASURES}

\section{Pain relief}

Authors commonly report on the results of analgesic trials using mean data with associated standard deviations, this is a problem as the data may be asymmetrically distributed and if used in meta-analyses will lead to potentially erroneous conclusions. ${ }^{20}$ It is therefore important to derive dichotomous data from the continuous data presented in trials before using the data in meta-analyses. The team at the Oxford Pain Relief Unit and Nuffield Department of Anaesthetics have derived a method for dichotomising this data; the detailed background and verification were published over three papers in the late 1990s. ${ }^{20-22}$ From the data presented in the trials, the proportion of patients achieving $50 \%$ pain relief (50\% maximum total pain relief [TOTPAR])) was calculated and used in the meta-analysis. Other Cochrane reviews have made use of these measures in their analyses. ${ }^{13-15}$ Summed pain intensity difference (SPID) essentially measures the same outcome as TOTPAR. If data were unavailable to calculate TOTPAR, SPID would have been calculated. If data on both TOTPAR and SPID were available, TOTPAR was chosen in preference. Outcomes were assessed for 2 hours and 6 hours post-dosing (where possible). For these dichotomous outcomes, the estimate of an intervention was expressed as risk ratios together with 95\% confidence intervals. 


\section{Table 3 Comparison of ibuprofen versus paracetamol}

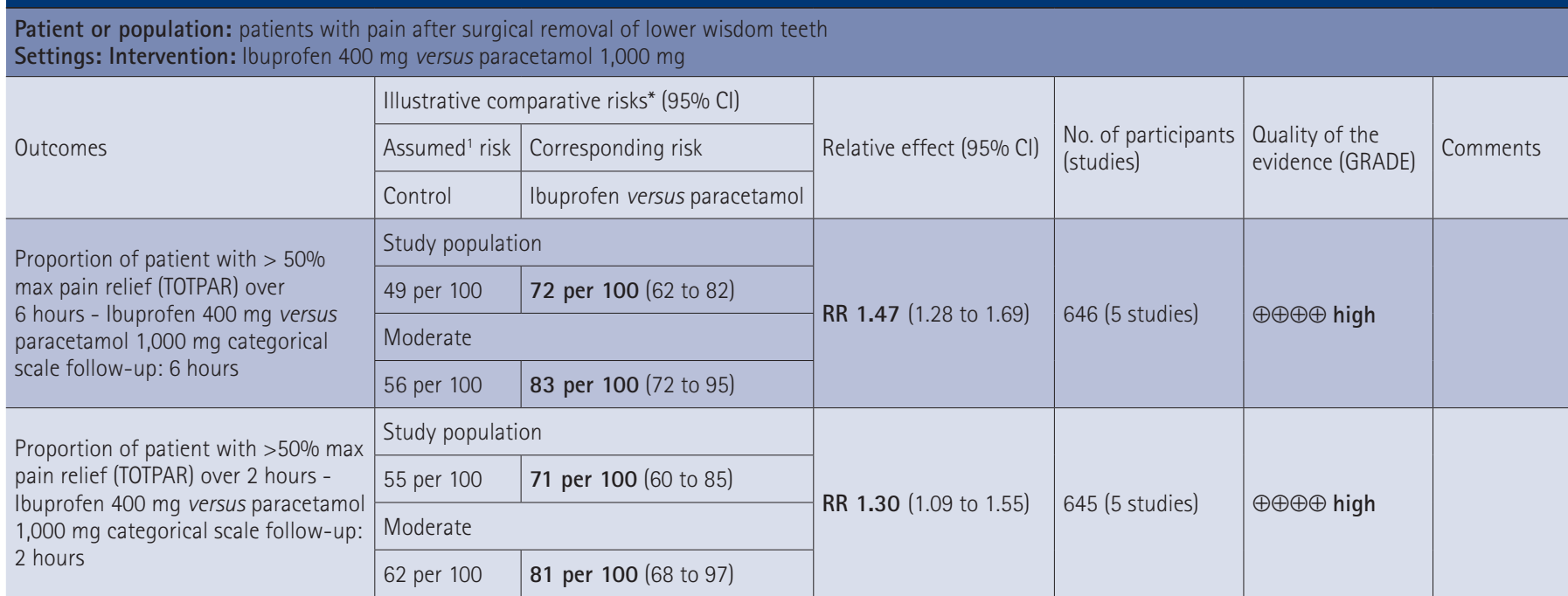

*The basis for the assumed risk (for example, the median control group risk across studies) is provided in footnotes. The corresponding risk (and its $95 \%$ confidence interval) is based on the assumed risk in the comparison group and the relative effect of the intervention (and its $95 \% \mathrm{CI})$. Cl: confidence interval; RR: risk ratio; OR: odds ratio. GRADE Working Group grades of evidence - High quality: further research is very unlikely to change our confidence in the estimate of effect. Moderate quality: further research is likely to have an important impact on our confidence in the estimate of effect and may change the estimate. Low quality: further research is very likely to have an important impact on our confidence in the estimate of effect and is likely to change the estimate. Very low quality: we are very uncertain about the estimate.

This is the median control group risk based on paracetamol being the control group.

\section{Use of rescue medication}

Data on the percentage of patients taking rescue medication over the study period were also included in a separate meta-analysis.

\section{RESULTS}

Seven studies were included in this review. ${ }^{10,11,23-27}$ They contained data on 2,241 participants. All of these studies included a direct comparison of ibuprofen to paracetamol or the combination of both agents in the same drug. The majority of the trials (six) were conducted in the USA, with one trial conducted in Puerto Rico. ${ }^{27}$ Four of the trials were completed in clinical research facilities, ${ }^{10,11,23,26}$ two in university dental hospitals ${ }^{25,27}$ and one in a private oral surgery clinic. ${ }^{24}$

\section{Characteristics of the participants}

The participants were broadly similar in the included trials; all contained the following exclusion criteria:

- History of significant disease

- Ongoing painful conditions (other than the third molar[s] scheduled for removal)

- Allergy/intolerance to the study drugs

- Patients currently taking long-term analgesics

- Malabsorption states (not mentioned in Mehlisch $1995^{26}$ )

- Gastrointestinal complaints (not mentioned in Mehlisch 199526)

- Psychotic illness or drug abuse (not mentioned in Mehlisch 199526)

- Concomitant medication that would interfere with the study drugs (not mentioned in Forbes $1990^{24}$

- Pregnancy and/or breastfeeding (not mentioned in Mehlisch 1995 ${ }^{26}$ )

- Migraine (not mentioned in Forbes $1990,{ }^{24}$ Hersh $2000^{25}$ or Olson $2001^{27}$ ).

Age ranges were broadly similar with 16-40 years accounting for the vast majority of participants.

\section{Characteristics of the interventions}

See Table 1 for a summary of the doses used in the included studies.

\section{Type of anaesthetic used}

In two studies, general anaesthetic with supplemental local anaesthetic was used. $^{24,26}$ Local anaesthetic alone was used in one study. ${ }^{27}$ Local anaesthetic with supplemental sedation was used in four studies, one using inhalation sedation with nitrous oxides, ${ }^{23}$ two with nitrous oxide, diazepam and a barbituate, ${ }^{10,11}$ and in one study 'most patients' received intravenous conscious sedation. ${ }^{25}$

\section{Number of doses of analgesic given}

For the purposes of data extraction in this review, only the data from the first postoperative dose were used. The patients were monitored for between 6 and 8 hours from this first dose before re-medication.

\section{Risk of bias in included studies}

Risk of bias was assessed using the five domains as described in Table 2. Figure 1 provides a summary of the risk of bias judgement in the included studies. 'A bias is a systematic error, or deviation from the truth, in results or inferences'. ${ }^{18}$ Bias in clinical trials can lead to underestimation or overestimation of the true effect of an intervention.

\section{Comparison one: ibuprofen versus paracetamol}

The most relevant comparison was between ibuprofen given as a $400 \mathrm{mg}$ dose and paracetamol given as a $1,000 \mathrm{mg}$ dose as these are the most commonly prescribed doses in clinical practice.

\section{Outcome TOTPAR - greater than 50\%} pain relief over 6 hours

The overall risk ratio was 1.47 (95\% CI 1.28 to 1.69 ; $p<0.00001$ ), indicating that $47 \%$ more patients achieved at least $50 \%$ of the maximum pain relief over 6 hours in the ibuprofen group.

\section{Outcome TOTPAR - greater than 50\% pain relief over 2 hours}

The overall risk ratio was 1.30 (95\% CI 1.09 to $1.55 ; \mathrm{p}<0.00001)$, indicating that $30 \%$ more patients achieved at least 50\% of the maximum pain relief over 2 hours in the ibuprofen group compared to the paracetamol group.

See Table 3 for analysis of this comparison.

\section{Comparison two: combined (ibuprofen and paracetamol) versus single drugs}

The two outcomes for TOTPAR were only based on data from one trial, ${ }^{10}$ therefore they 


\section{Table 4 Comparison of combined versus single drugs}

Patient or population: patients with pain after surgical removal of lower wisdom teeth

Settings: Intervention: Combined (ibuprofen $400 \mathrm{mg}$ and paracetamol 1,000 mg) versus single drugs

\begin{tabular}{|c|c|c|c|c|c|c|}
\hline \multirow{3}{*}{ Outcomes } & \multicolumn{2}{|c|}{ Illustrative comparative risks* (95\% Cl) } & \multirow{3}{*}{ Relative effect $(95 \% \mathrm{Cl})$} & \multirow{3}{*}{$\begin{array}{l}\text { No. of participants } \\
\text { (studies) }\end{array}$} & \multirow{3}{*}{$\begin{array}{l}\text { Quality of the } \\
\text { evidence (GRADE) }\end{array}$} & \multirow{3}{*}{ Comments } \\
\hline & Assumed' risk & Corresponding risk & & & & \\
\hline & Control & $\begin{array}{l}\text { Combined (ibuprofen and } \\
\text { paracetamol) versus single } \\
\text { drugs }\end{array}$ & & & & \\
\hline \multirow{4}{*}{$\begin{array}{l}\text { Proportion of patient with } \\
>50 \% \text { max pain relief (TOTPAR) } \\
\text { over } 6 \text { hours - paracetamol } \\
1,000 \text { mg/ibuprofen } 400 \mathrm{mg} \\
\text { versus paracetamol 1,000 mg \&t } \\
\text { ibuprofen } 400 \mathrm{mg} \text { categorical } \\
\text { scale follow-up: } 6 \text { hours }\end{array}$} & \multicolumn{2}{|c|}{ Study population } & \multirow{4}{*}{ RR 1.77 (1.32 to 2.39 ) } & \multirow{4}{*}{170 (1 study) } & \multirow{4}{*}{$\oplus \oplus \oplus \ominus$ moderate $^{1}$} & \\
\hline & 38 per 100 & 67 per 100 (50 to 90$)$ & & & & \\
\hline & \multicolumn{2}{|l|}{ Moderate } & & & & \\
\hline & 38 per 100 & 67 per 100 (50 to 91) & & & & \\
\hline \multirow{4}{*}{$\begin{array}{l}\text { proportion of patient with > } \\
50 \% \text { max pain relief (TOTPAR) } \\
\text { over } 2 \text { hours - paracetamol } \\
1,000 \mathrm{mg} / \text { ibuprofen } 400 \mathrm{mg} \\
\text { versus paracetamol } 1,000 \mathrm{mg} \text { and } \\
\text { ibuprofen } 400 \mathrm{mg} \text { categorical } \\
\text { scale follow-up: } 2 \text { hours }\end{array}$} & Study populatic & & \multirow{4}{*}{ RR 1.29 (0.91 to 1.85 ) } & \multirow{4}{*}{170 (1 study) } & \multirow{4}{*}{$\oplus \oplus \oplus \ominus$ moderate $^{1}$} & \\
\hline & 37 per 100 & 48 per 100 (34 to 68 ) & & & & \\
\hline & \multicolumn{2}{|l|}{ Moderate } & & & & \\
\hline & 37 per 100 & 48 per 100 (34 to 68$)$ & & & & \\
\hline
\end{tabular}

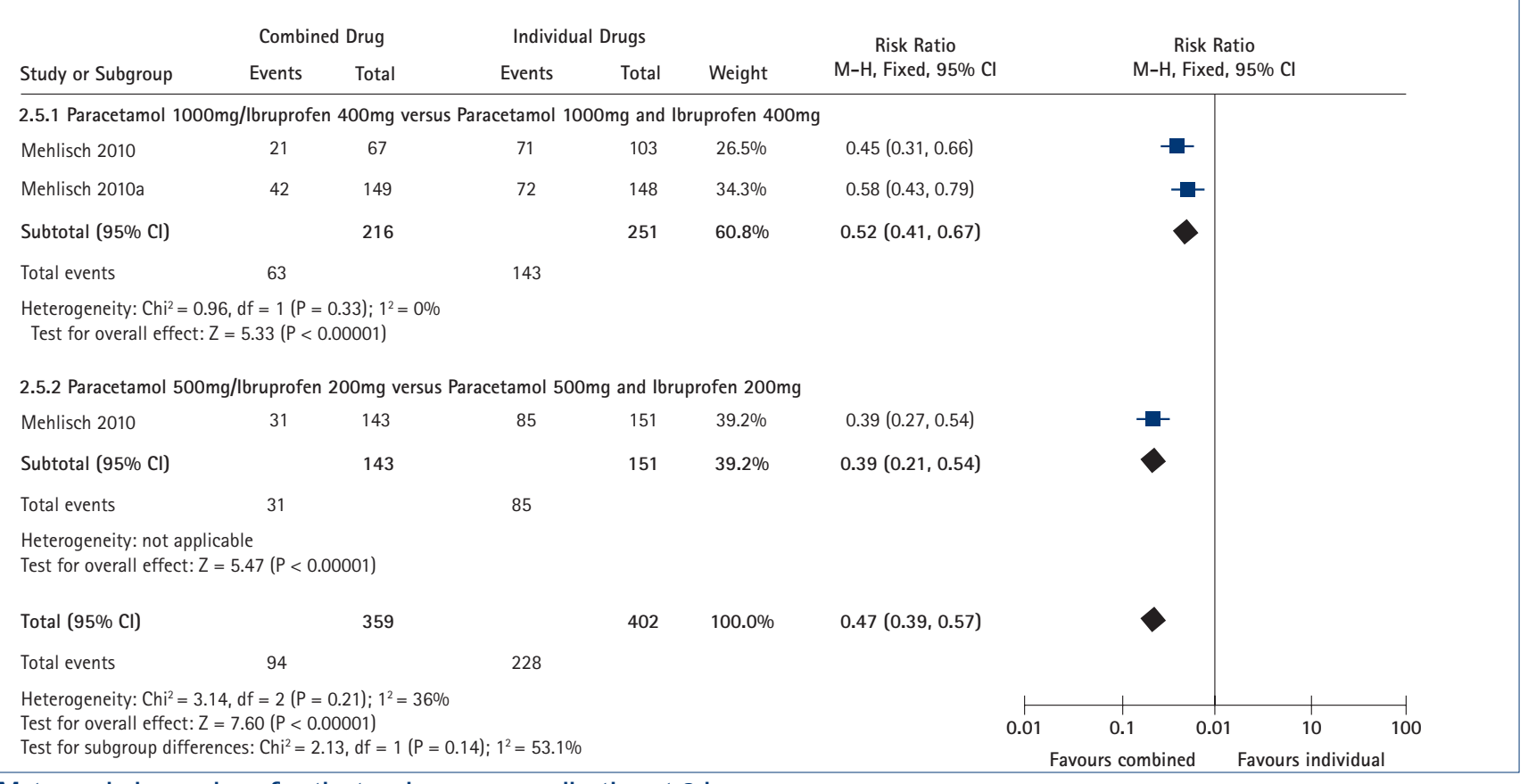

\section{Fig. 2 Meta-analysis: number of patients using rescue medication at 8 hours}

cannot be considered as meta-analyses. All of the comparisons were between paracetamol $1,000 \mathrm{mg}$ and ibuprofen $400 \mathrm{mg}$ in the same tablet, and the same constituent drugs given as single tablets. It was not possible to derive TOTPAR and/or SPID data as the trial ${ }^{11}$ used a two-stage design; despite contact with the authors, we did not obtain the specific data required to dichotomise the trial results for meta-analysis.

\section{Outcome TOTPAR - greater than $50 \%$ pain relief over 6 hours}

This comparison demonstrates a risk ratio of 1.77 (95\% CI 1.32 to $2.39 ; p=0.0002)$, indicating that $77 \%$ more patients achieved at least $50 \%$ of the maximum pain relief over 6 hours in the combined drug group as did in the single drug group.

\section{Outcome TOTPAR - greater than $50 \%$ pain relief over 2 hours}

This outcome demonstrates a risk ratio of 1.29 (95\% CI 0.91 to 1.85 ; $p=0.15$ ), indicating that 29\% more patients achieved at least $50 \%$ of the maximum pain relief over 2 hours in the combined drug group as did in the single drug group.

\section{Number of patients using rescue medication at 8 hours}

The results of two studies were included in this analysis, ${ }^{10,11}$ which compared the efficacy of a combination of paracetamol 1,000 mg/500 mg with ibuprofen $400 \mathrm{mg} / 200 \mathrm{mg}$ in the same pill with the individual constituent drugs taken together. The lower dose was included here in order to perform a meta-analysis of single $v s$ combined drugs. There was no difference between the subgroups $(p=0.39)$, and the overall risk ratio was 1.67 (95\% CI 1.48 to $1.90 ; p<0.00001$ ) indicating that $67 \%$ fewer patients used rescue medication over 
the first 6 hours in the combined drug group compared to the individual constituent drug group at this dose.

See Table 4 and Figure 2 for further details.

\section{Summary of findings}

Using the software GRADE profiler 3.6, the quality of the body of evidence was assessed for both comparisons: ibuprofen versus paracetamol, and combined (ibuprofen and paracetamol) versus single drugs. TOTPAR and use of rescue medication were assessed as SPID is measuring the same outcome as TOTPAR. A summary of findings for the two comparisons is shown in Table 3 and Table 4. These tables show that all of the outcomes for comparing ibuprofen versus paracetamol were found to be of quality. The comparisons for combined (ibuprofen and paracetamol) versus single drugs for TOTPAR are both of moderate quality as they were downgraded due to being based on data from single studies and the imprecision of estimate. The evidence for use of rescue medication was assessed as high quality.

\section{CONCLUSIONS}

There is high quality evidence that ibuprofen is superior to paracetamol at doses of $400 \mathrm{mg}$ ibuprofen and 1,000 $\mathrm{mg}$ paracetamol; these are the most frequently used doses in clinical practice. This review proves ibuprofen to be superior to paracetamol in terms of analgesic efficacy when used postoperatively for pain management following the surgical removal of lower wisdom teeth. It is important to be aware that the data in this review only relate to single dose postoperative usage of the trial drugs. The combined drugs containing both agents show promising outcomes, with metaanalysis of the use of rescue medication at 8 hours providing high quality evidence that the combined drugs are superior to the single drugs. This funding is echoed by a recent Cochrane review that found that participants had a smaller chance of requiring rescue medication over 8 hours if they took the combined drug compared to the individual agents. ${ }^{28}$ It has been suggested that these findings could be due to the formulation of the combined drug having a faster onset of analgesia. ${ }^{29}$ However, we found that at 2 hours postoperatively, there was no significant difference between the paracetamol, ibuprofen and combined drug, implying that the drug had a 'delayed' effect relative to the single drug. That is, at 6 hours the combined drug was more effective. All drugs studied in this review are generally considered safe with minimal side effects noted when used for short-term pain relief. It is important to remember that many patients are able to tolerate paracetamol and ibuprofen, and on the basis of evidence in this review prescribing both analgesics either as individual tablets or in combination would take advantage of their differing pharmacological properties and achieve adequate pain relief for patients following the surgical removal of lower third molar teeth.

1. Bailey $E$, Worthington $H V$, van Wijk $A$, Yates J $M$, Coulthard P, Afzal Z. Ibuprofen and/or paracetamol (acetaminophen) for pain relief after surgical removal of lower wisdom teeth. status and date: Cochrane Database Syst Rev 2013; 12: CD004624.

2. McArdle L, Renton T. The effects of NICE guidelines on the management of third molar teeth. Br Dent $\rfloor$ 2012; 213: E8-E8.

3. Colorado-Bonnin M, Valmaseda-Castellon E, BeriniAytes L, Gay-Escoda C. Quality of life following lower third molar removal. Int J Oral Maxillofac Surg 2006; 35: 343-347.

4. Conrad S M, Blakey G H, Shugars D A, Marciani R D, Phillips C, White R P Jr. Patients' perception of recovery after third molar surgery. J Oral Maxillofac Surg 1999; 57: 1288-1294.

5. Savin J, Ogden G R. Third molar surgery-a preliminary report on aspects affecting quality of life in the early postoperative period. Br J Oral Maxillofac Surg 1997; 35: 246-253.

6. Ogden G, Bissias E, Ruta D, Ogston S. Quality of life following third molar removal: a patient versus professional perspective. Br Dent J 1998; 185: 407-410.

7. Cooper S, Beaver W. A model to evaluate mild analgesics in oral surgery outpatients. Clin Pharmacol Ther 1976; 20: 241-250.

8. Bailey E, Patel N, Coulthard P. Non-steroidal antiinflammatory drugs for pain after oral surgery. Oral Surgery 2014; epub ahead of print.

9. Coulthard P, Bailey E, Patel N. Paracetamol (acetaminophen) for pain after oral surgery. Oral Surgery 2014; epub ahead of print.

10. Mehlisch D R, Aspley S, Daniels S E, Bandy D P. Comparison of the analgesic efficacy of concurrent ibuprofen and paracetamol with ibuprofen or paracetamol alone in the management of moderate to severe acute postoperative dental pain in adolescents and adults: a randomized, double-blind, placebo-controlled, parallel-group, single-dose, two-centre, modified factorial study. Clinical Ther 2010; 32: 882-895

11. Mehlisch D R, Aspley S, Daniels S E, Southerden K A, Christensen K S. A single-tablet fixed-dose combination of racaemic ibuprofen/paracetamol in the management of moderate to severe postoperative dental pain in adult and adolescent patients: a multicentre, two-stage, randomized, double-blind, parallel-group, placebo-controlled, factorial study. Clinical Ther 2010; 32: 1033-1049.

12. Mehlisch D R. The efficacy of combination analgesic therapy in relieving dental pain. J Am Dent Asoc 2002; 133: 861-871.
13. Toms L, McQuay H J, Derry S, Moore R A. Single dose oral paracetamol (acetaminophen) for postoperative pain in adults. Cochrane Database Syst Rev 2008; 4: CD004602.

14. Derry C, Derry S, Moore R A, McQuay H J. Single dose oral ibuprofen for acute postoperative pain in adults. Cochrane Database Syst Rev 2009; 3 : CD001548.

15. Weil K, Hooper L, Afzal Z et al. Paracetamol for pain relief after surgical removal of lower wisdom teeth. Cochrane Database Syst Rev 2007; 3: CD004487.

16. Moore R A, Derry S, McQuay H J, Wiffen P J. Single dose oral analgesics for acute postoperative pain in adults. Cochrane Database Syst Rev 2011; 9: CD008659.

17. Moore, R, McQuay H. Single-patient data metaanalysis of 3453 postoperative patients: oral tramadol versus placebo, codeine and combination analgesics. Pain 1997; 69: 287-294

18. Higgins J P, Green S. Cochrane handbook for systematic reviews of interventions. Vol 4. Wiley, 2011.

19. Cochrane Oral Health Group. Cochrane Oral Health Group. Online information available at http://ohg. cochrane.org/cochrane-oral-health-group (Accessed March 2014).

20. Moore A, Moore O, McQuay H, Gavaghan D. Deriving dichotomous outcome measures from continuous data in randomised controlled trials of analgesics: use of pain intensity and visual analogue scales. Pain 1997; 69: 311-315.

21. Moore A, McQuay H, Gavaghan D. Deriving dichotomous outcome measures from continuous data in randomised controlled trials of analgesics. Pain 1996; 66: 229-237.

22. Moore A, McQuay H, Gavaghan D. Deriving dichotomous outcome measures from continuous data in randomised controlled trials of analgesics: verification from independent data. Pain 1997; 69: 127-130.

23. Daniels S, Reader S, Berry P, Goulder M. Onset of analgesia with sodium ibuprofen, ibuprofen acid incorporating poloxamer and acetaminophen-a single-dose, double-blind, placebo-controlled study in patients with post-operative dental pain. Eur J Clin Pharmacol 2009; 65: 343-353.

24. Forbes J A, Butterworth G A, Burchfield W H, Beaver W T. Evaluation of ketorolac, aspirin, and an acetaminophen-codeine combination in postoperative oral surgery pain. Pharmacotherapy 1990; 10: 77S-93S.

25. Hersh E V, Levin L M, Cooper S A et al. Ibuprofen liquigel for oral surgery pain. Clin Ther 2000; 22: 1306-1318.

26. Mehlisch $D R$, Jasper $R D$, Brown $P$, orn $S H_{\text {, }}$ McCarroll K, Murakami A A. Comparative study of ibuprofen lysine and acetaminophen in patients with postoperative dental pain. Clinical Ther 1995; 17: 852-860.

27. Olson N Z, Otero A M, Marrero I et al. Onset of analgesia for liquigel ibuprofen $400 \mathrm{mg}$, acetaminophen $1000 \mathrm{mg}$, ketoprofen $25 \mathrm{mg}$, and placebo in the treatment of postoperative dental pain. J Clin Pharmacol 2001; 41: 1238-1247.

28. Derry C J, Moore R A, Derry S. Single dose oral ibuprofen plus paracetamol (acetaminophen) for acute postoperative pain. Cochrane Database Syst Rev 2013; 6: CD010210.

29. Daniels S E, Goulder M A, Aspley S, Reader S. A randomised, five-parallel-group, placebo-controlled trial comparing the efficacy and tolerability of analgesic combinations including a novel singletablet combination of ibuprofen/paracetamol for postoperative dental pain. Pain 2011; 152: 632-642. 